\title{
A Segurança Energética da China e as Reações dos EUA*
}

Diego Pautasso** e Lucas Kerr de Oliveira***

\section{Introdução}

objetivo deste trabalho é discutir a segurança energética da China, seus desafios e as reações estratégicas dos Estados Unidos da América (EUA). Os recursos energéticos, de um modo geral, e o petróleo, de modo específico, tendem a assumir papel decisivo neste contexto da profunda reorganização de poder no sistema internacio-

\footnotetext{
* Artigo recebido em novembro de 2007 e aprovado para publicação em abril de 2008. Os autores agradecem às críticas do prof. dr. Marco Aurélio Chaves Cepik.

** Doutorando em Ciência Política pela Universidade Federal do Rio Grande do Sul (UFRGS) e professor de Relações Internacionais da Escola Superior de Propaganda e Marketing (ESPM), de Geografia do Colégio Militar de Porto Alegre (CMPA) e do Curso Diplomacia. E-mail: dpautasso@ bol.com.br. *** Doutorando em Ciência Política pela Universidade Federal do Rio Grande do Sul (UFRGS) e professor substituto pelo Departamento de Ciência Política da UFRGS. E-mail: lucaskerr@yahoo.com.br.
} 
nal desde o fim da Guerra Fria. Assim, tal quadro afeta as pretensões da China de lograr sua ascensão à condição de potência mundial, assim como a tentativa dos EUA de evitarem a emergência de pólos de poder desafiantes.

Por um lado, a ascensão da China ampara-se em acelerada modernização econômica e em forte projeção internacional de poder. No plano regional, o país tem assumido a condição de centro do processo de reorganização da Ásia-Pacífico: a leste, integrando-se à dinâmica dos novos e velhos Tigres Asiáticos; e a oeste, integrando-se à Organização de Cooperação de Shangai (OCS; em inglês, Shanghai Cooperation Organisation (SCO)). ${ }^{1}$ No plano internacional, a diplomacia e o comércio exterior chinês logram forte e crescente penetração em outras regiões do globo, incluindo o Sul da Ásia, Oriente Médio, América Latina e África.

Por outro lado, os EUA buscam recompor sua hegemonia ${ }^{2}$ por meio da reorganização do sistema internacional e da superação dos seus problemas econômicos. Desde 1970, os EUA se deparam com a multipolarização ${ }^{3}$ do sistema internacional e, ao mesmo tempo, com os crescentes problemas econômicos domésticos. A multipolarização tem evoluído por meio de movimentos diversos: a descolonização de países da periferia, como a maioria dos países afro-asiáticos; a industrialização e liderança regionais de países semiperiféricos como Brasil, Índia, África do Sul e China; a reconstrução, o desenvolvimento e a crescente independência da União Européia; a recuperação da Rússia e de seu protagonismo diplomático; e a projeção do Japão e dos Tigres Asiáticos. Os processos de integração regionais revelam uma readequação das bases territoriais de acumulação do capital e, ao mesmo tempo, uma articulação político-diplomática entre os espaços global e nacional. Estes movimentos de longa duração acabam por diluir o poder dos EUA e por projetar novos contornos ao sistema internacional. 
Além disso, a economia norte-americana, com seus déficits comerciais e orçamentários, bem como com a crescente competitividade tecnológica dos pólos emergentes, demonstra dificuldades de novo tipo. É claro que os déficits norte-americanos são sustentáveis por recursos de poder que não se apresentam para outros países do mundo, mesmo cêntricos. Os EUA emitem a moeda que é meio de pagamento e reserva de valor da economia mundial, de modo que o país tem a vantagem de quitar as importações (muitas vezes oriundas de transnacionais norte-americanas situadas em outros países) e a dívida externa com sua própria moeda. Entretanto, é preciso considerar que há limites para a emissão de moeda, uma vez que esta se ancora na base material da economia. De qualquer forma, os problemas domésticos dos EUA estão fortemente imbricados na questão da segurança energética, na ascensão chinesa e na reorganização do sistema internacional.

Nesse sentido, o petróleo apresenta-se como fundamental à sobrevivência dos EUA e ao êxito da ascensão chinesa. Para a China a compra do petróleo (e outras commodities) tem sido utilizada para fortalecer a segurança energética e ampliar sua inserção em outros mercados, alterando a correlação de forças mundiais por meio de seu comércio exterior. Para os EUA, o petróleo apresenta-se ainda como um mecanismo de controle indireto dos principais pólos desafiantes, ou seja, China, União Européia e Japão. Além do crescimento das disputas entre os grandes e novos consumidores, há o declínio da extração petrolífera em regiões tradicionalmente produtoras, incluindo EUA e Mar do Norte.

A batalha pelos recursos estratégicos parece cada vez mais complexa, especialmente no que se refere ao petróleo. O caso das disputas sino-americanas pelos hidrocarbonetos em áreas de exploração mais recentes, como África e Ásia Central, é ilustrativo da nova tendência. Esta batalha deve ser, portanto, um dos elementos-chave na transição em curso no sistema internacional, condicionando fatores estruturais 
na política internacional neste início do século XXI: a reorganização de forças e os alinhamentos diplomáticos; a capacidade institucional e a possível escalada de violência; e a redefinição da importância e do protagonismo do continente africano.

Nos anos 1970, os membros do Ministério das Indústrias de Petróleo da China haviam batalhado para a assimilação de avançada tecnologia ocidental para perfuração submarina (SPENCE, 1995, p. 588). Ironicamente, o petróleo, que esteve no centro do debate acerca das formas de conduzir a modernização da economia chinesa nos anos 1970, agora está no centro do debate acerca da rápida ascensão do país à condição de potência mundial. Da mesma forma, os EUA que se alçaram à condição de potência após a descoberta do petróleo no século XIX na Pensilvânia agora percebem neste recurso fóssil novamente uma precondição para a manutenção de seu status de poder.

\section{A Ascensão Chinesa e o Desafio à Hegemonia dos EUA}

A ascensão da China tem sido um dos principais desafios à condição hegemônica dos EUA. Se, nos anos 1970, a aproximação sino-americana produziu nova distribuição de poder no mundo, influenciando o fim da Guerra Fria, a partir dos anos 1990 tal relacionamento tem projetado fortes contradições. Não há dúvida de que os fatores determinantes na conformação do sistema internacional devem ser, de um lado, a ascensão do Dragão Chinês e, de outro, as possíveis reações dos EUA ao deslocamento de suas posições de poder.

A ascensão da China tem se dado por "uma espécie de gigantesca e prolongada NEP [Nova Política Econômica]" (LOSURDO, 2004, p. 67), quer dizer, por meio da modernização como prioridade na superação do atraso e do isolamento diplomático em que a China se encontrava. As reformas desencadeadas por Deng Xiaoping no final 
dos anos 1970, por intermédio da política das Quatro Modernizações (agricultura, indústria, ciência e tecnologia e defesa), eram a ferramenta política para tal propósito. De forma geral, o desenvolvimentismo da Ásia-Pacífico foi uma resposta ao ciclo depressivo que se irradiou do centro da economia mundial após meados dos anos $1970{ }^{4}$ no caso chinês, a conjuntura internacional adversa estava articulada aos distúrbios e crises decorrentes da Revolução Cultural.

Nesse contexto, a Ásia-Pacífico foi assumindo a condição de pólo dinâmico da acumulação capitalista, especialmente em virtude da projeção dos Tigres Asiáticos a partir da captação dos grandes investimentos japoneses na região (VIZENTINI; RODRIGUES, 2000). A China percebeu o espaço regional como fundamental para uma inserção ativa no ciclo de globalização que se abria. Os investimentos estrangeiros, principalmente dos chineses da diáspora, tornavam-se o ponto central do financiamento do desenvolvimento do país.

Os fluxos comerciais e as iniciativas diplomáticas evidenciam que a China se tornou o centro gravitacional da região. Isto quer dizer que o acelerado crescimento chinês nessas últimas décadas tem implicado no crescente deslocamento das posições de poder dos EUA e do Japão na Ásia-Pacífico. E, à medida que a China reforça sua base de poder doméstico e regional, aumenta a sua projeção internacional de poder.

Os indicadores da Tabela 1 mostram a forte base de poder material (doméstico) pelo qual a China produz sua inserção internacional.

Nesse sentido, as relações sino-americanas vão se revestindo de profunda complexidade, gerando graves contradições. Do lado chinês, o mercado e os investimentos norte-americanos são fundamentais. É por meio do superávit comercial acumulado de US\$ 1,095 trilhão entre 1990 e 2005 que a China fortalece suas reservas internacionais e aumenta sua capacidade de investimento. Já com relação aos investimentos estrangeiros, os EUA participaram apenas com 6,5\%, sendo 


\section{Tabela 1}

Evolução do Desenvolvimento da China

\begin{tabular}{|l|l|}
\hline $\begin{array}{l}\text { Taxa de crescimento real de salário médio } \\
\text { (1991-2004) }\end{array}$ & $9,63 \%$ ao ano \\
\hline $\begin{array}{l}\text { Evolução do Produto Interno Bruto (PIB) per } \\
\text { capita }\end{array}$ & $\begin{array}{l}\text { US\$ 55,62 (1980) => US\$ } \\
1.100,48(2003)\end{array}$ \\
\hline Crescimento real do PIB médio (1990-2004) & $9,3 \%$ ao ano \\
\hline $\begin{array}{l}\text { PIB em Purchasing Power Parity (PPP; em } \\
\text { português, Paridade de Poder de Compra) }\end{array}$ & $\begin{array}{l}\text { US\$ 455,5 (1980) => US\$ } \\
7.546,6(2004)\end{array}$ \\
\hline $\begin{array}{l}\text { Superávit comercial com os EUA acumulado } \\
\text { (1990-2005) }\end{array}$ & US\$ 1,095 trilhão \\
\hline Superávit comercial acumulado (1990-2004) & US\$ 291,7 bilhões \\
\hline Reservas internacionais & $\begin{array}{l}\text { US\$166 (1990) => US\$ 875 } \\
\text { bilhões (2005) }\end{array}$ \\
\hline Investimentos em ativos fixos & $\begin{array}{l}\text { US\$ 98,9 (1990) => US\$ 741,3 } \\
\text { bilhões (2004) }\end{array}$ \\
\hline Dívida externa/PIB (2004) & $14,1 \%$ \\
\hline Relação poupança/PIB nominal (2004) & $49,7 \%$ \\
\hline
\end{tabular}

Fonte: National Bureau of Statistics of China (1980-2005).

a maioria, 62\%, oriundos da Ásia. Do lado norte-americano, os capitais e o mercado dos chineses são fundamentais para os EUA. Enquanto os capitais sustentam os déficits por meio da compra de títulos do Tesouro, o mercado chinês proporciona um dinâmico espaço de acumulação para suas multinacionais. As contradições que se têm acumulado decorrem dos ganhos diferenciados produzidos pela interdependência. Ou seja, o relacionamento bilateral tende a enfraquecer a economia dos EUA, debilitando a capacidade produtiva e as contas externas, ao mesmo tempo que permite à China fortalecer sua capacidade diplomática, pela condição de credora, e econômica, pelo ritmo que permite imprimir à modernização (PAUTASSO, 2006, p. 54-64).

Se os EUA têm se apresentado como nação hegemônica desde o pós-guerra, o fim da Guerra Fria coloca a China na condição de maior desafio aos EUA. Como pólo emergente de poder, a China tem 
buscado uma inserção internacional cada vez mais ativa, fortalecendo laços com diversos países ou blocos em todo o mundo. Daí a importância do alinhamento chinês ao G-22, criado no âmbito da Organização Mundial do Comércio (OMC); das pressões da embaixada chinesa na Organização das Nações Unidas (ONU) pelo perdão das dívidas do Terceiro Mundo; da recente abertura comercial total a produtos dos 35 países mais pobres do mundo; da decisão de apoiar a reforma no Conselho de Segurança da Organização das Nações Unidas (CS/ONU); da opção pela transferência de tecnologia e construção de usinas hidrelétricas e termelétricas para países africanos (Angola, Etiópia, Guiné), entre outras ações políticas (JABBOUR, 2006, p. 37-38, p. 191). Ilustrativo deste movimento foi o novo satélite de comunicações geoestacionário nigeriano, construído, lançado e financiado pela China. ${ }^{5}$ A política externa chinesa tem sido, portanto, elemento de redefinição das relações centro-periferia na nova ordem mundial.

A inserção internacional ativa da China torna-se assim objeto de debate nos EUA. Alguns acadêmicos norte-americanos consideram fundamental, para conter a ascensão da China, impedir o incremento das suas capacidades militares; preservar as "regras do jogo" com um mínimo de mudança e esforço; manter a ordem política renovando as alianças existentes; construir novas alianças para proteger os Estados potencialmente ameaçados pelo poder ascendente; e preparar-se para a guerra a fim de manter a posição de poder dos EUA e de seus aliados. Por isso, a política externa dos EUA para a China teria que estar voltada para: 1) perseguir a cooperação, integrando a China ao sistema internacional e à democracia; 2) evitar que a China adquira capacidade de ameaçar os interesses dos EUA na Ásia e além; e 3) preparar-se para lidar com uma China afirmativa, com grandes capacidades militares e como poder emergente (SWAINE; TELLIS, 2000, p. 234-240).

As considerações destes estrategistas norte-americanos não têm dado conta da realidade, pois é justamente preservando as "regras do 
jogo" que a China tem logrado uma posição de crescente projeção de poder no cenário internacional. Em outras palavras, tem conseguido uma acelerada modernização econômica e desenvolvimento tecnológico; o fortalecimento de suas capacidades militares; e a ampliação das suas alianças diplomáticas e de sua projeção internacional. O que mais interessa ao governo da China no curto e médio prazo é, pois, a preservação do status quo internacional, com ajustes que facilitem sua inserção.

A idéia de "ascensão pacífica" (BIJIAN, 2005) apenas reflete o êxito da modernização e da inserção externa da China com estas condições internacionais - e não a recusa ingênua ao uso da força em caso de interrupção unilateral de tal processo ou violação de soberania. Da mesma forma, a defesa da multipolaridade pela China visa evitar uma coalizão antichinesa e, ao mesmo tempo, diluir o poder do sistema internacional com projeção de novos pólos de poder. De qualquer maneira, cabe destacar que, enquanto a China não tem histórico de agressões externas (somente quando foi governada por dinastias estrangeiras, manchu e mongol), os EUA, ao contrário, desde sua Independência (1776) nunca ficaram mais de uma década sem intervir militarmente fora de seus domínios territoriais. ${ }^{6}$

Por isso, os líderes chineses têm percebido a segurança nacional e regional fortemente ligada à ascendência dos EUA na região. Esta constatação decorre de três razões principais: geopolítica, visando conter a expansão da Organização do Tratado do Atlântico Norte (OTAN) para a Ásia Central; econômica, objetivando colocar sob controle sino-russo os recursos naturais da Ásia Central; e estratégica, procurando garantir a estabilidade das fronteiras ocidentais da China, minimizando a penetração do terrorismo e do separatismo e reconstruindo a antiga Rota da Seda (CHUNG, 2004, p. 993, p. 997-1.003).

A consolidação do poder da China depende de forte base regional, o que explica sua projeção para leste e oeste. Para leste, tornando-se o 
núcleo da Bacia do Pacífico, centralizando os fluxos econômicos e ampliando sua projeção diplomática por meio da Asean+3. ${ }^{7}$ Já para oeste, tornando-se o núcleo, ao lado da Rússia, da Organização de Cooperação de Shangai (OCS), criada em 2001. Esta é, aliás, uma aproximação de natureza estratégica da China e da Rússia, assim como de países da Ásia Central, tais como Cazaquistão, Quirguistão, Tadjiquistão e Usbequistão. A OCS proporciona a conformação de um pólo de poder com autonomia estratégica, pois há complementaridade entre China e Rússia: a primeira sendo um país com enorme acumulação de capital e potencial mercado consumidor; e a segunda, com enormes reservas de recursos naturais, especialmente petróleo e gás natural, destacado desenvolvimento no campo tecnológico-militar e poder diplomático (G8 e CS/ONU). Quer dizer, o oeste chinês, a Ásia Central e a Sibéria russa podem tornar-se o espaço eurasiático de ligação da Ásia-Pacífico à Europa, reduzindo sensivelmente a capacidade dos EUA reafirmarem sua hegemonia.

A recuperação da Rússia e a arrancada industrial da China, agora articuladas politicamente pela OCS, estão recriando desconfianças nos estrategistas dos EUA acerca da contenção da Eurásia. O espaço que liga a Europa Oriental à China e à Ásia Central, passando pela Rússia, chamado pela geopolítica clássica de heartland, está criando condições objetivas de ter novamente protagonismo no sistema internacional. Se o heartland anti-sistêmico (socialismo real) que moldou a Guerra Fria foi contido pelo cordão sanitário e depois colapsou (1989-1991), com a OCS este espaço ganha novamente vitalidade, se não para dominar o mundo, como supunha o geógrafo Halford John Mackinder, ao menos para ter notável inserção internacional. Enfim, a Eurásia é uma região estratégica que motivou a geopolítica clássica de Mackinder ${ }^{8}$ no início do século XX, mas que retorna ao primeiro plano das análises em pensadores contemporâneos. Esta grande massa continental se tornou o centro das atenções de autores que abordam aspectos estratégico-militares e o poder das grandes 
potências (BRZEZINSKI, 1997; 2001); aspectos culturais, religiosos e civilizacionais (HUNTINGTON, 1997); aspectos demográfico-históricos (TODD, 2003); e ainda aspectos ligados aos recursos naturais, principalmente energéticos, como o petróleo e o gás (KLARE, 2001; 2003).

$\mathrm{Na}$ Ásia Oriental, a China tem justificado o acercamento entre os países asiáticos como forma de contenção dos EUA (VIZENTINI; RODRIGUES, 2000, p. 106). Ao conformar sua base de poder regional e projetar-se internacionalmente, a China desafia a hegemonia dos EUA. No entanto, diferente de outros pólos desafiantes, a China combina, de forma singular, recursos de poder fundamentais: grande território e população; abundância de recursos naturais; dinâmico e diversificado parque produtivo; notável desenvolvimento científico-tecnológico; Estado com uma elite com tradição e com projeto definido; diplomacia apta a desenvolver uma inserção global não subordinada; matriz cultural milenar e coesa capaz de projetar-se além do espaço nacional.

Os EUA ainda mantêm o controle, ou pelo menos vantagem significativa, nos principais meios de manutenção de seu poder em escala global, como: (I) tecnologias militares de ponta; (II) sistema financeiro mundial; (III) meios de comunicação de massa; (IV) organizações internacionais multilaterais; e (V) recursos naturais estratégicos. Entretanto, os dilemas da segurança nacional dos EUA são revelados no plano neoconservador chamado "Project for the New American Century". ${ }^{9}$ Esta estratégia de política internacional para a manutenção da superioridade dos EUA tem, entretanto, aprofundando fissuras no sistema internacional.

A nova ordem mundial deve estruturar-se como produto da compatibilização entre a ascensão da China e as reações dos EUA. Por um lado, a transformação pela qual passa a China, se concluída com sucesso, pode resultar em uma dramática transição de poder no sistema 
internacional (SWAINE; TELLIS, 2000, p. 1). Por outro lado, a transição não catastrófica para uma nova ordem mundial será determinada pela resistência norte-americana à adaptação e à conciliação (ARRIGHI; SILVER, 2001, p. 298). Um dos fatores centrais nesta transição deve estar (como tem estado) relacionado à segurança energética, principalmente com as disputas pelos recursos fósseis (petróleo e gás natural). Como o controle sobre o petróleo foi uma das bases para a construção e manutenção da hegemonia dos EUA ao longo do século XX (TORRES FILHO, 2004), parece pouco crível que os EUA relevem ao segundo plano suas preocupações com a segurança energética e o acesso ao petróleo.

\section{Problemas de Segurança Energética}

A consolidação do capitalismo após a Revolução Industrial projetou os recursos energéticos ao centro das atividades produtivas. Como a Revolução Industrial foi uma revolução também no consumo de energia, os recursos energéticos tornaram-se indispensáveis ao desenvolvimento das economias nacionais. Com o uso intensivo de energia na era industrial, a segurança energética passou a ser uma preocupação constante não apenas dos mercados consumidores, das corporações e/ou dos meios de transporte, mas principalmente dos Estados.

Ao longo do século XX, a preocupação com a segurança energética tornou-se central em qualquer planejamento, levando governantes e estrategistas a desenvolverem análises acerca dos riscos de paralisia da economia ou de violações da soberania, com considerações inclusive de logística militar. Afinal, sem energia não é possível movimentar tropas, tanques, navios ou aeronaves, nem mesmo garantir o funcionamento de sistemas de comunicação, vigilância e defesa (OLIVEIRA, 2007, p. 111). Mesmo o advento da "sociedade pós-industrial” e da Revolução Científico-Tecnológica não tornou menos 
importante o consumo energético, especialmente dos recursos fósseis. ${ }^{10}$ Aliás, a Revolução Científico-Tecnológica não proporcionou ainda um paradigma energético alinhado às inovações tecnológicas dos outros campos da economia.

Daí a importância da diversificação das fontes de energia, bem como da garantia de seu fornecimento (como recursos nacionais ou sob controle nacional). Tanto em caso de guerra como em situações de paz, a vulnerabilidade energética pode colapsar a economia de um ou de vários países. Uma das principais formas de minimizar a vulnerabilidade, já identificada desde o início do século XX e defendida por Churchill (YERGIN, 1993), seria reduzir a dependência de um único fornecedor. Naquela época, esta função era ocupada pelo Irã, como principal fornecedor de petróleo para o Reino Unido. ${ }^{11}$

A descolonização e a formação dos países no Oriente Médio, sob forte controle das potências ocidentais, evidenciam a relevância histórica da segurança energética. Este controle das fontes, associado aos baixos preços do barril de petróleo, em termos históricos, condicionou o aparente desinteresse pela segurança energética. Afinal, os preços somente se tornaram altos, constrangendo o desenvolvimento de vários países, em períodos históricos relativamente curtos, como na década de 1970 e primeira metade dos anos 1980. Ainda assim, entre os anos 1930 e 1950, inúmeros países criaram empresas estatais para a gestão dos recursos fósseis e para o apoio ao desenvolvimento nacional.

Os preços reduzidos no período 1985-1999 pareciam mesmo ter tornado o petróleo outra commodity qualquer. De 1998 - quando o preço caiu pela última vez abaixo de US\$10,00 por barril - até o ano presente, o aumento do preço do petróleo tem provocado novas discussões a respeito da vulnerabilidade econômica ou militar em função da dependência energética de grandes países (EUA, Japão) ou regiões (União Européia). Além disso, a possível escassez relativa 
dos recursos energéticos não renováveis (diminuição das novas descobertas/reservas em relação ao crescimento do consumo), associada às pressões de grupos ambientalistas e à crescente demanda de pólos emergentes, como Índia e China, ${ }^{12}$ está desfazendo o aparente desinteresse pela segurança energética que marcou os anos 1990. Mais que isso, a segurança energética pode tornar-se o "pomo da discórdia" na política internacional.

No caso específico da China, a segurança energética passa pela garantia do fornecimento para suportar as taxas elevadas de crescimento que o país vem apresentando nas últimas três décadas. Não somente no âmbito energético o crescimento chinês tem impacto na economia mundial. Os preços dos recursos minerais - tais como ferro, estanho, cobre, entre outros - e agroalimentares têm apresentado significativas elevações. É exatamente na segurança energética, porém, que se situa a preocupação da elite chinesa, especialmente em virtude do recrudescimento da política externa dos EUA, fortemente condicionada pelas pressões políticas do setor petrolífero e do complexo industrial-militar.

O problema da segurança energética, especialmente para potências como EUA e China, passou a envolver disputas recentes relacionadas à aquisição de empresas do setor petrolífero. Um caso notório é o da tentativa de aquisição de uma empresa petrolífera dos EUA por uma multinacional chinesa: a Chinese National Offshore Oil Corporation (CNOOC), semi-estatal petrolífera chinesa, tentou adquirir a norte-americana Unocal em 2005. Cerca de 70\% das reservas de hidrocarbonetos da Unocal estão localizadas na Ásia Central e região do Mar Cáspio, sendo esta empresa a maior acionista do gasoduto transafegão. Como os EUA haviam investido na mudança do regime afegão e na ocupação militar do país a partir de 2001 (KLARE, 2005), esta tentativa de compra da Unocal foi bloqueada pelo governo dos EUA, que alegou motivos de segurança nacional. A CNOOC havia oferecido US \$ 18,5 bilhões pela Unocal, mas essa intervenção 
do governo norte-americano, vetando uma transação de mercado, orientou a venda da empresa para outra empresa dos EUA, a Chevron-Texaco, mesmo que por US\$ 1,5 bilhão a menos (OLIVEIRA, 2007, p. 71-72). Em resumo, segurança energética, desenvolvimento nacional e políticas de Estado entrecruzam-se de forma evidente sem possibilidade de livre atuação das forças de mercado.

\section{Desafios à Segurança Energética Chinesa e Planejamento de Estado}

A segurança energética influencia decisivamente a inserção externa dos países e seus alinhamentos diplomáticos. A China manteve-se auto-suficiente em petróleo durante a maior parte da Guerra Fria. Esta vantagem lhe permitiu manter certa distância das crises petrolíferas dos anos 1970, bem como se posicionar diplomaticamente de forma autônoma em relação aos principais conflitos envolvendo países exportadores de petróleo no Oriente Médio naquela época. Mesmo na Guerra do Golfo em 1991, a China absteve-se na votação sobre a formação de uma força internacional para expulsar o Iraque do Kuwait.

Entretanto, a crescente dependência de recursos energéticos fósseis tem forçado a China a ter maior protagonismo na sua política externa no que se refere aos países com grandes reservas de petróleo e gás natural. Durante a preparação dos EUA para a intervenção no Iraque, a China posicionou-se contrariamente ao emprego da força bélica. Mais recentemente, a China vem se esforçando para impedir a imposição de sanções ao Irã e ao Sudão, só que agora justamente para preservar ou ampliar sua ascensão sobre os recursos fósseis deste país. Nestes dois últimos casos, além da ênfase da política externa chinesa de não-ingerência em assuntos domésticos, há inegavelmente a preocupação com a sua segurança energética. Isto é, Irã e Sudão têm importantes contratos de fornecimento de recursos energéticos fósseis 


\section{Gráfico 1}

\section{Produção, Consumo e Importação de Petróleo pela China*}

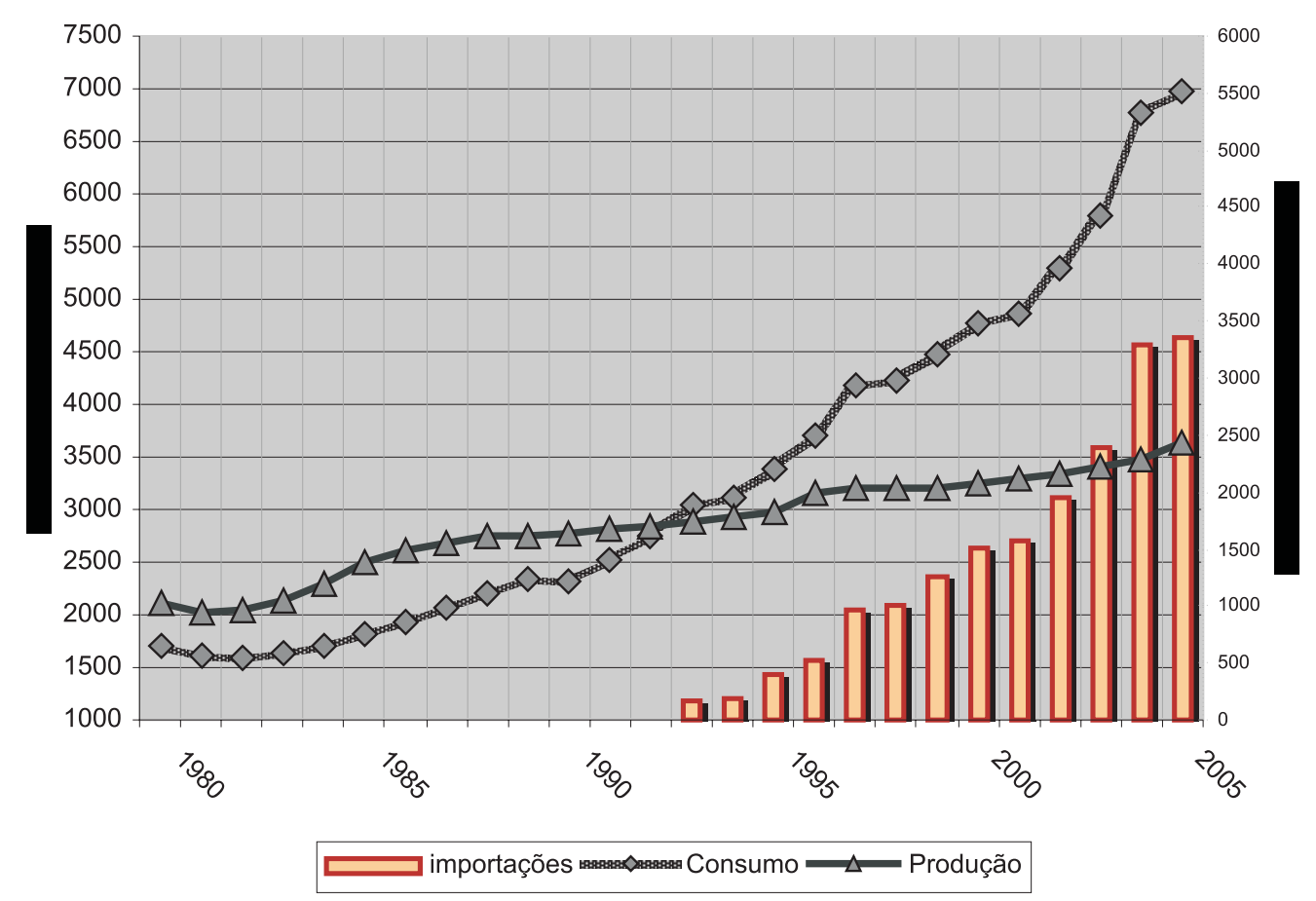

* A produção e o consumo estão representados na escala da esquerda, enquanto a escala da direita corresponde ao volume total das importações por ano.

Fontes: BP statistical review of world energy 2007 (BRITISH PETROLEUM, 2007a) e BP statistical review full report workbook (BRITISH PETROLEUM, 2007b).

como gás natural e petróleo para a China, ao mesmo tempo em que são objetos de ofensiva diplomática e militar dos EUA.

As duas décadas de crescimento econômico acelerado, com aumento do consumo de energia ainda mais rápido, produziram a alteração da posição da China. Pode-se identificar pelo menos dois grandes marcos interessantes nestas mudanças: em 1993, quando a China se torna um importador de petróleo (Gráfico 1) e, em 2000, quando o consumo das reservas totais chinesas começa a declinar.

Segundo a Organização dos Países Exportadores de Petróleo (OPEP; em inglês, Organization of the Petroleum Exporting Countries (OPEC)), as reservas chinesas cresceram quase continuamente nas últimas décadas, passando de pouco mais de 13,3 bilhões de barris 
em 1980 para 15,9 bilhões em 1990 e 18,3 bilhões em 2001, quando as novas descobertas não conseguiram mais recompor as reservas consumidas (OPEC Interactive Annual Statistical Bulletin 2006c). O resultado disso é uma redução lenta, porém constante, no volume destas reservas que em 2004 caíram para 17 bilhões de barris mesmo diante de todo o esforço empregado para procurar novos poços.

Considerando que é conhecido o fato de que um tempo variável após o auge ou pico das descobertas costuma ocorrer o pico da produção, ${ }^{13}$ parece que este foi outro grande ponto de inflexão na estratégia chinesa. ${ }^{14}$ Afinal, mesmo tendo se tornado um importador líquido já em 1993, parece que apenas com o início da depleção de suas reservas em 2000-2001 a China se tornou mais agressiva na sua busca por petróleo estrangeiro. Tanto que suas grandes empresas petrolíferas, que antes concentravam seus esforços em adquirir empresas ou poços já em funcionamento, passaram a investir em exploração e prospecção.

Logicamente, existem outras explicações possíveis para esta mudança na atuação chinesa, como o aumento dos preços no mercado internacional, ou até uma reação a uma busca também mais agressiva por parte de outras potências importadoras. A própria maturidade das companhias petrolíferas chinesas é um fator interessante. A experiência adquirida nas empresas e poços adquiridos nos anos 1990, especialmente o know-how necessário para exploração, desenvolvimento, prospecção, comércio internacional e gestão de negócios, levou um tempo para gerar uma massa crítica significativa. Mesmo assim, o início da depleção do volume total das reservas chinesas parece ser determinante nesta mudança de estratégia.

Isso porque, apesar de certas flutuações no volume total, entre $1993 \mathrm{e}$ 2000, as reservas chinesas cresciam, pouco, mas ainda cresciam. Passaram de 16,4 para 17,9 bilhões de barris de petróleo, o que dava aos planejadores chineses uma possibilidade (estreita) de contar com 
possíveis novas descobertas no país, que poderiam ocorrer em um ritmo que permitisse não só recompor o volume total das reservas, mas até mesmo sustentar a continuidade do seu crescimento. Com o início da depleção destas reservas e projeções que apontavam para uma produção máxima de cerca de 3,8 milhões de barris/dia (mb/d) para $2015,{ }^{15}$ ficou claro que a China não poderia mais planejar seu desenvolvimento com base no aumento da produção doméstica, mas tentar assegurar o fornecimento externo.

Em 2003, a China ultrapassou o Japão como segundo maior consumidor mundial de petróleo, com 5,3 mb/d. Em 2005, a China consumiu $6,9 \mathrm{mb} / \mathrm{d}$ e, em 2006, atingiu a marca de 7,4 mb/d. Considerando que a produção nacional aumentou de 3,4 para 3,6 mb/d entre $2003 \mathrm{e}$ 2006, o resultado foi um crescimento abrupto das importações chinesas, que atingiram $3,88 \mathrm{mb} / \mathrm{d}$. Estas representavam $35 \%$ do consumo nacional em 2003 e ultrapassaram 50\% em 2006. ${ }^{16}$

A China não sofreu nenhum grande corte no fornecimento de petróleo na sua história recente (DAOJIONG, 2006), o que dificulta, portanto, avaliar as possíveis respostas que o país poderá dar a um desafio que possa comprometer o desenvolvimento da economia e afetar a dinâmica da sociedade. A segurança energética da China passa por cenários diversos, desde um possível corte na produção de um grande produtor global como a Arábia Saudita, que significaria 9 milhões de barris por dia a menos no mercado mundial, até o corte em algum grande fornecedor chinês como Irã, Sudão ou Angola. Na hipótese de colapso envolvendo um único fornecedor, em tempos de paz, provavelmente o mercado global de petróleo absorveria pequenos cortes como os que ocorreram na Venezuela em 2003.

O risco de um corte deste tipo também inclui cenários em que guerras regionais causem a interrupção do fluxo de petroleiros em algum estreito ou chokepoint, como Ormuz ou Malaca. E inclui o cenário de um possível bloqueio naval por parte dos EUA no caso de uma guerra 
envolvendo Taiwan (BLAIR et al., 2006; WENMU, 2006). Estas preocupações estariam entre as razões que levam a China a construir grandes gasodutos e oleodutos atravessando o país, mesmo que estes sejam aparentemente inviáveis do ponto de vista econômico (DAOJIONG, 2006, p. 7-9).

Mais do que isso, o planejamento de Estado do governo chinês para a segurança energética nacional tem de enfrentar esta problemática em curto prazo, equacionando diversos fatores, tais como: as fontes de financiamento, o crescimento econômico forte, a proteção ambiental e a capacidade técnico-administrativa. Assim, o planejamento estatal chinês percebe a segurança energética como possível vulnerabilidade, mas também como grande possibilidade para impulsionar o desenvolvimento nacional.

Por isso, as políticas estatais voltadas para a infra-estrutura energética tornaram-se centrais ao desenvolvimento nacional, já que combinam objetivos cruciais de longo prazo. Primeiro, a integração territorial e a interiorização do desenvolvimento por meio da infra-estrutura energética, como os dutos oriundos do nordeste e noroeste do país que abastecem o litoral (sudeste). Segundo, a integração regional por meio da ligação infra-estrutural entre China e Rússia e Ásia Central, impulsionando a Organização de Cooperação de Shangai e aumentando o número de fornecedores. ${ }^{17}$ Terceiro, o aumento da eficiência no uso da energia, o que implica desenvolvimento das forças produtivas, já que a China consumiu no ano passado $15 \%$ da energia do planeta para produzir 5,5\% do Produto Interno Bruto (PIB) global em 2006. Quarto, a redução dos problemas ambientais pela redução do uso de combustíveis fósseis. Quinto, a utilização da capacidade ociosa da indústria de bens de produção e de bens de capital "puxados" pela indústria da construção civil. Sexto, a dependência energética pela diversificação das fontes (hidrelétricas, termonucleares, eólica e biomassa). 
As políticas de governo para redução da dependência energética pela diversificação e elevação do percentual de fontes não fósseis na matriz energética têm sido significativas. Na China, três quartos da matriz energética assentam-se no carvão mineral ou no petróleo, o que causa sérios danos ambientais, principalmente por causa da chuva ácida e das conseqüentes perdas agrícolas ou doenças humanas.

As fontes hidráulicas têm recebido grandes investimentos, pois o país tem grande potencial hidrelétrico com baixa capacidade instalada. Além disso, tais obras atuam no controle das constantes cheias dos rios, no comércio interior em virtude das hidrovias e no aumento da receita tributária local. As fontes termonucleares também estão sendo desenvolvidas. Mais do que fonte de energia, as usinas termonucleares estão ligadas à manutenção da soberania nacional, ao desenvolvimento tecnológico, à formação de cientistas, ao comércio de urânio ou de reatores, entre outros. A energia eólica e da biomassa também estão recebendo atenção. As iniciativas voltadas pela a energia eólica culminaram, por exemplo, no parque criado no litoral de Shangai pelas empresas energéticas chinesas, a Shanghai Environment e a Shanghai Huadian Electric Power, com capacidade de gerar 46,69 milhões de quilowatts-hora ao ano. Ao mesmo tempo, vem crescendo o uso da biomassa para a produção de energia, incluindo a ampliação da instalação de milhões de pequenos biodigestores e milhares de médio porte. A importação de biomassa também tem aumentado, principalmente por meio de acordos do governo chinês para aquisição de óleo de palma do sudoeste asiático, visando produzir biodiesel, bem como a importação de álcool do Brasil.

O uso do gás natural tem se intensificado também. A principal obra de gás natural é o gasoduto oeste-leste, que liga as ricas reservas de Xinjiang a Shangai, em um trajeto de $4.221 \mathrm{~km}$. Neste caso, a obra de infra-estrutura obedece à solução de problemas ambientais, interiorização do desenvolvimento, redução dos ímpetos separatistas, entre outros (JABBOUR, 2006). Vale observar que a China está constru- 
indo dezesseis terminais no litoral para receber gás natural liquefeito (GNL). Recentemente, o terminal de Shenzhen, operado pela companhia estatal CNOOC, deve receber fornecimento equivalente a US $\$ 18,3$ bilhões em gás durante 25 anos por meio de contrato com a Austrália. Aliás, a China é hoje o segundo maior parceiro comercial da Austrália, atrás somente do Japão. A CNOOC tem ampliado as atividades ligadas ao GNL, tendo assinado contratos de US\$ 5 bilhões para exploração de gás natural e de US $\$ 11$ bilhões para instalação de plantas de liquefação de gás no Irã.

Apesar destas e de outras iniciativas para diversificar a matriz energética, a rápida ampliação da demanda por recursos fósseis, como carvão mineral e petróleo, constrange a segurança energética chinesa. Tanto que, apesar das grandes reservas nacionais, até mesmo o carvão mineral pode tornar-se um recurso crescentemente importado.

\section{A Política Energética dos EUA e a Contenção da China}

Os EUA têm parte da sua política internacional direcionada pelos interesses petrolíferos e pela garantia de sua própria segurança energética há muito mais tempo do que a China. Isso se deve basicamente a três razões: (I) a proteção dos interesses e investimentos das companhias petrolíferas norte-americanas instaladas no exterior começou no início do século XX quando estas passaram a atuar além de suas fronteiras, mas se intensificou a partir de 1947, quando os EUA passaram a importar petróleo; (II) a partir de 1970, o país atingiu sua capacidade máxima de produção e passou a ser realmente dependente das importações, até mesmo para aumentar seu consumo doméstico; (III) o declínio do volume da produção doméstica vem se acelerando desde então, aumentando significativamente a dependência do petróleo importado e, por sua vez, dos seus fornecedores. 
A evolução da estratégia dos EUA de controle do petróleo esteve historicamente ligada à construção e à manutenção da hegemonia. Mesmo que até os choques petrolíferos (1973-79) os EUA fossem pouco dependentes das importações de recursos energéticos fósseis, existe uma correspondência entre os três grandes padrões de ordenamento do mercado petrolífero mundial ${ }^{18}$ e as mudanças sofridas pela hegemonia norte-americana nestes períodos (TORRES FILHO, 2004, p. 341).

A Tabela 2 ilustra algumas tendências interessantes sobre a segurança energética da China, bem como a inserção dos EUA nesta questão. Com a crescente dependência de importações de petróleo a partir dos anos 1980 (chegando atualmente a 65\% do consumo doméstico), os EUA acentuaram sua ascendência sobre outras regiões, visando a manutenção da segurança energética.

\section{Tabela 2}

China e EUA: Importação de Petróleo segundo os Países e Regiões Exportadoras (2006)

\begin{tabular}{lll}
\hline $\begin{array}{l}\text { País / região exportadora } \\
\text { de petróleo }\end{array}$ & \multicolumn{2}{l}{ País importador (x mil barris/dia) } \\
\hline & EUA & China \\
\hline NAFTA & 4.003 & 8 \\
América do Sul e Caribe & 2.708 & 262 \\
África & 2.659 & 923 \\
Oriente Médio & 2.276 & 1.490 \\
Europa & 1.120 & 9 \\
Ex-URSS & 370 & 489 \\
China & 27 & - \\
Ásia-Pacífico-Oceania & 240 & 693 \\
Outros & 237 & 13 \\
Total importado & 13.612 & 3.887 \\
\hline
\end{tabular}

Fonte: BP statistical review of world energy 2007 (BRITISH PETROLEUM, 2007a, p. 20).

Praticamente metade das importações de petróleo dos EUA tem origem no continente americano $(49,4 \%)$, principalmente no âmbito do próprio Tratado de Livre Comércio da América do Norte (em inglês, 
North American Free Trade Agreement (NAFTA)) (28,2\%). Contudo, a África e o Oriente Médio têm papel relevante para o fornecimento de petróleo para os EUA: a primeira é responsável por 18,4\% das importações e o segundo, por 17,3\%. No caso da China, $62,9 \%$ de suas importações de petróleo são oriundas do Oriente e da África, especificamente $40,1 \%$ do primeiro e $22,8 \%$ da segunda. Já as importações regionais da Ásia-Pacífico e Oceania representam 21,3\% e da ex-União das Repúblicas Socialistas Soviéticas (ex-URSS), $11,7 \%$.

Ao observarmos os fornecedores de petróleo dos EUA e da China, podemos constatar questões reveladoras. De um lado, tal observação demonstra que os EUA possuem uma significativa segurança energética relativa, na medida em que a maior parte do seu fornecimento vem do seu próprio hemisfério, onde este mantém forte liderança. De outro, evidencia as pretensões norte-americanas de controlarem o Oriente Médio, África e Ásia Central, de onde a China obtém quase três quartos das suas importações de petróleo.

Entretanto, a análise em perspectiva demonstra que a ascendência chinesa tem sido crescente e bem-sucedida, mesmo nas áreas historicamente de influência dos EUA, como na Venezuela. ${ }^{19}$ Além disso, apesar do crescimento da demanda por petróleo na China, o país, com mais de quatro vezes a população dos EUA, importa apenas um quarto do volume total importado pela economia norte-americana.

Como a Tabela 2 também permite visualizar, o Oriente Médio é o principal fornecedor de petróleo para a China. Porém, grande parte das ações chinesas visando incrementar suas importações de petróleo fora do Oriente Médio é voltada para a Ásia Central e a Rússia, ou seja, para dentro da OCS, ou para a África. A relevância percentual da região Ásia-Pacífico no fornecimento petrolífero chinês tem caído nos últimos anos enquanto cresce a importância da África e ex-URSS. 


\section{A Segurança Energética da China e as Reações dos EUA}

É pertinente lembrar que a emergência da China está aumentando a demanda por petróleo e simultaneamente os EUA intensificam suas ações militares e diplomáticas nesta grande região exportadora de hidrocarbonetos e de significativa instabilidade política, que vai da África (do Golfo da Guiné até o Sudão), passa pelo Oriente Médio e Cáucaso e estende-se até a Ásia Central. Daí a importância da presença militar crescente dos EUA na região. Considerando as novas bases norte-americanas construídas, a presença de forças navais, as intervenções militares e os acordos no campo da defesa estabelecidos após a Guerra Fria, nota-se que a maior parte destas ações envolve rotas de petróleo e áreas de produção. Se observarmos as bases militares na Ásia Central (Usbequistão), no Oriente Médio (Iraque e Arábia Saudita) e na África (Djibuti), bem como a presença das forças navais no Golfo da Guiné, Mar Vermelho e Golfo Pérsico, fica evidente a importância destas regiões na segurança energética dos EUA.

Destaque-se que cerca de $80 \%$ do petróleo exportado pelo Oriente Médio é transportado por navios, dos quais todos atravessam o estreito de Ormuz, por onde passam 21,2 mb/d ou cerca de um quarto do consumo mundial de petróleo. As principais rotas de petróleo que saem desta região passam por mais três importantes estreitos (chokepoints), a saber, os estreitos de Bab el-Mandab, do Canal de Suez e de Malaca, por onde passam respectivamente, 4,3, 4,7 e 15,8 mb/d. Ou seja, pelo estreito de Malaca, no Sudoeste Asiático, entre a Indonésia, Cingapura e Malásia, circularam cerca de $18 \%$ do consumo mundial de petróleo em 2005. Outros estreitos importantes incluem o de Bósforo, de Dardanelos, o de Gibraltar, o Canal do Panamá, além da passagem de Moçambique (entre Moçambique e Madagascar) e de Taiwan (entre Taiwan e China).

Todas as rotas petrolíferas que passam por estes estreitos são estratégicas e, ao mesmo tempo, oferecem um grande risco ao mercado mundial, já que uma guerra regional poderia interromper parte signi- 
ficativa do transporte mundial de petróleo, afetando não apenas as grandes potências, mas regiões inteiras do mundo.

\section{Novas Regiões na Segurança Energética Chinesa: Os Casos da África e da OCs}

A necessidade de garantir a segurança energética tem levado o governo e a diplomacia da China a intensificarem a atuação em diversas regiões. Nessa recente ofensiva diplomática chinesa visando o suprimento de petróleo e gás natural, destacam-se a África e os países da OCS. São regiões que possuem grandes reservas e potencialidades, ao mesmo tempo em que apresentam competição mais reduzida entre as potências mundiais, se comparadas com o Oriente Médio.

A projeção da política externa da China para os países africanos produtores de petróleo e gás natural relaciona-se a fatores político-diplomáticos, comerciais e econômicos. No âmbito político-diplomático, a China tem adotado a ênfase na não-intervenção em assuntos domésticos, na valorização da soberania nacional, bem como na aproximação das respectivas agendas políticas nos organismos multilaterais. No âmbito do comércio exterior, o governo chinês tem assumido déficits comerciais planejados, viabilizando muitas economias periféricas ao absorver suas commodities a preços em crescente elevação. No âmbito econômico, os investimentos externos realizados pela China em infra-estrutura, com financiamento e apoio técnico, têm dado impulso decisivo à construção nacional. As exigências diplomáticas chinesas restringem-se ao reconhecimento de "uma só China" ${ }^{20}$ e aos compromissos bilaterais no comércio exterior.

As disputas estratégicas pelo petróleo na África têm sido crescentes, envolvendo principalmente China e EUA. A razão desta nova tendência se explica por fatores internos e externos ao continente africa- 
no. Internamente, houve um aumento da produção de petróleo na África após a relativa marginalização do continente nos anos 1990. Externamente, a crescente demanda energética da China desde 1993 defronta-se com a resistência dos EUA à perda de suas posições de poder.

A Tabela 3 demonstra que as reservas africanas foram as que mais cresceram entre 1985 e 2005 . As reservas passaram de 57 para 114,3 bilhões de barris, ou seja, passaram de 7,4\% para 9,52\% do total das reservas mundiais, um crescimento de cerca de $200 \%$. No mesmo período de vinte anos, a produção africana cresceu de $5,4 \mathrm{mb} / \mathrm{d}$ para $9,83 \mathrm{mb} / \mathrm{d}$. Isto é, o continente africano já representava em 2005 mais de $12 \%$ da produção mundial de petróleo, com um crescimento da produção de $81 \%$.

Tabela 3

Petróleo na África (1985-2005)*

\begin{tabular}{llclc}
\hline \multicolumn{4}{c}{ Reservas de Produção } \\
\hline Região & \multicolumn{3}{c}{ Bilhões de bbl } & \multicolumn{2}{c}{ Milhares de b/d } \\
\hline & 1985 & 2005 & 1985 & 2005 \\
África Subsaariana & 21,3 & 58,6 & 2.261 & 5.348 \\
África do Norte & 35,7 & 55,7 & 3.172 & 4.487 \\
Total África & $\mathbf{5 7 , 0}$ & $\mathbf{1 1 4 , 3}$ & $\mathbf{5 . 4 3 3}$ & $\mathbf{9 . 8 3 5}$ \\
\% do total mundial & $\mathbf{7 , 4 \%}$ & $9,52 \%$ & $9,45 \%$ & $12,13 \%$ \\
\hline
\end{tabular}

* O volume das reservas está expresso em bilhões de barris (bbl) e a produção em milhões de barris por dia (b/d).

Fonte: BP statistical review of world energy 2006 (BRITISH PETROLEUM, 2006).

Se considerarmos em conjunto a produção do continente africano, ela superou em mais de $3 \mathrm{mb} / \mathrm{d}$ a produção dos EUA (6,83 mb/d), ficou pouco acima da produção russa $(9,55 \mathrm{mb} / \mathrm{d})$, só perdendo para a Arábia Saudita (11 mb/d), o maior produtor mundial em 2005. Entre 1985 e 2005, a produção de petróleo da África cresceu $81 \%$. Se for considerada apenas a parcela da produção mundial que é exportada, o peso da África aumenta ainda mais, chegando a representar 
$14,88 \%$ do total de petróleo exportado no mundo durante o ano de 2005. Somente a África Subsaariana representou quase 10\% do total exportado pelo mundo. Ora, considerando o relativo isolamento do continente africano nos anos 1990, a penetração diplomática tornava-se mais fácil e atraente.

Como a África Subsaariana superou a África do Norte nas exportações de petróleo mundiais, especialmente o Golfo da Guiné se tornou foco de disputas sino-americanas.

Esta área de exploração recente inclui principalmente a Nigéria, Angola e Guiné Equatorial, que representam mais de 37\% do petróleo produzido na África. Além disso, o petróleo do Golfo da Guiné tem custos de produção relativamente baixos (US\$ 7.500 e US\$ 8 mil por barril produzido por dia), superiores apenas aos do Oriente Médio (US\$ 4 mil e US\$ 4.500 investidos por barril/dia), enquanto na Ásia e nos países da Organização para Cooperação e Desenvolvimento Econômico (OCDE) a relação entre investimento e produção tem um custo muito superior (na faixa de US\$ 12 a 13 mil investidos por barril produzido por dia).

Estes números refletem não apenas a importância de atores subsaarianos no mercado petrolífero mundial, mas também o fato de que o Golfo da Guiné, especificamente a região que vai da Nigéria a Angola, tornou-se um espaço de interesse geopolítico vinculado à segurança energética das grandes potências, especialmente China e EUA.

Além do petróleo, a África possui 8,2\% das reservas mundiais de gás natural, totalizando 14,825 trilhões de metros cúbicos. ${ }^{21}$ Apesar disso, a produção é bem menor, já que o consumo de gás no continente é relativamente reduzido e as exportações se concentram na África do Norte. No futuro, a África Subsaariana deve se tornar mais importante em termos de exportações de gás natural quando alguns dos terminais de liquefação de gás (localizados na Nigéria, Angola, Egito e Argélia), atualmente em construção, estiverem prontos. 
Na última cúpula do Fórum de Cooperação China-África (em inglês, Forum on China-Africa Cooperation (Focac)), realizada em novembro de 2006, o presidente da China, Hu Jintao, prometeu dobrar a ajuda ao continente, oferecendo mais US $\$ 5$ bilhões em crédito para os próximos três anos, sendo US\$ 3 bilhões em empréstimos preferenciais, além de dobrar o número de produtos africanos isentos de importação na China. Este terceiro encontro do Focac teve o significado simbólico de representar meio século de relações da China com a África e, principalmente, de indicar as intenções da política externa chinesa para o continente.

A Organização de Cooperação de Shangai, formada em 2001, sob liderança da China e da Rússia, também guarda fortes relações com a segurança energética chinesa e com as possíveis respostas dos EUA. Este processo de integração regional, que inclui ainda países da Ásia Central como Usbequistão, Quirguistão, Tadjiquistão e Cazaquistão, é revelador de novas tendências emergindo na política internacional. Além da segurança energética, a iniciativa chinesa visa a criação de uma esfera de influência e de parcerias estratégicas que podem reorganizar as forças do sistema internacional.

Os objetivos da OCS foram sintetizados no espírito de Shangai com cinco "Cs": confiança, comunicação, cooperação, coexistência e comum interesse. Tais objetivos estão ligados na verdade à dissuasão da insurgência islâmica, como no Xinjiang e na Chechênia, e à ascendência dos EUA sobre a Ásia Central, aumentada após os atentados de 11 de setembro. É importante destacar que a China se tornou membro formal de um grupo regional que não é exclusivamente de orientação econômica (CHUNG, 2004, p. 994).

Embora os objetivos ultrapassem a segurança energética da China, esta é uma das metas centrais da diplomacia chinesa para o nascente mecanismo de integração regional. A produção e o consumo de petróleo da OCS situaram-se, respectivamente, em 720 milhões e 452 
milhões de toneladas em 2004. Em 2005, $11 \%$ do petróleo importado pela China veio da OCS, ${ }^{22}$ e inúmeras obras de infra-estrutura energética estão sendo feitas na região. Ora, sabe-se que esta região junto ao Mar Cáspio deve adentrar com força no mercado de hidrocarbonetos nas próximas décadas. Sabe-se também que, desde 2006, a Rússia tornou-se o maior produtor de petróleo do mundo.

Mais do que segurança energética, ao alçar-se além da Ásia e do centro do sistema internacional (EUA e União Européia), a China está buscando dar continuidade a dois pontos centrais da sua agenda externa. De um lado, a construção de uma ordem mundial multipolar mais equilibrada, que dilua o peso estratégico dos EUA ao criar e/ou fortalecer novos pólos de poder emergentes e novos eixos na política internacional. De outro lado, a consecução da condição da China como potência mundial em paridade com os EUA.

\section{Considerações Finais}

A busca chinesa por segurança energética passa pela diversificação de fontes internas, mas principalmente pela garantia de fornecimento externo. Ou seja, a segurança energética significa, internamente, a sustentabilidade do desenvolvimento nacional e, externamente, a necessidade de acesso e, se possível, controle das principais fontes mundiais de hidrocarbonetos. O que, por sua vez, significam novas e mais intensas disputas com a potência hegemônica, no caso os EUA. Nesse sentido, o governo da China tem uma política energética que contempla o planejamento e os investimentos domésticos, bem como as alianças diplomáticas que garantem o suprimento de petróleo e gás natural.

Dessa forma, se as relações econômicas e políticas sino-americanas guardam profundas contradições, a segurança energética talvez seja o núcleo de tais contradições. É ilustrativa desta nova conjuntura a intensificação das disputas pelo petróleo na África e na Ásia Central. 
Por um lado, percebe-se a intensificação das ações de força dos EUA, que passam pelo Afeganistão, Iraque e, agora, Irã, além da ampliação de sua influência por meios indiretos, como a derrubada do governo na Geórgia ou o estabelecimento de bases militares no Usbequistão. Por outro lado, as iniciativas da China para sua segurança energética expressam-se tanto nos investimentos na África quanto na consolidação da OCS. E a ascendência político-econômica nos países da OCS demonstra o protagonismo da política externa da China.

Cabe destacar primeiro que a África foi o continente onde predominaram as novas descobertas de petróleo na última década e que a China está se aproveitando do "vácuo" de poder decorrente da marginalização do continente após a Guerra Fria. A cúpula do Fórum de Cooperação China-África de 2006 evidencia a dimensão que tem assumido esta interação, já que os investimentos e a ofensiva diplomática do governo da China têm sido importantes. A evolução do comportamento dos fornecedores de petróleo na África pode ser fundamental para o entendimento da segurança energética da China e do reposicionamento dos EUA.

Segundo, que a OCS tem o atual maior produtor mundial (a Rússia) e uma importante nova área de exploração (o Mar Cáspio). Somadas, estas áreas representaram cerca de $40 \%$ do petróleo importado pela China em 2005, com uma tendência de ascensão significativa na última década. Além disso, para a Rússia, a China pode significar o contrapeso à dependência do mercado consumidor europeu de energia.

A geopolítica ${ }^{23}$ da construção dos gasodutos e oleodutos na Ásia Central e na bacia do Mar Cáspio diz muito sobre o jogo de poder e influência na região. Todavia, mais que isto, diz muito sobre a segurança energética e a ascensão da China e sobre as respostas dos EUA a tal reorganização de forças no sistema internacional. Da mesma 
forma, o continente africano deve apresentar-se como um novo espaço de disputas e acomodação de forças no mundo.

De qualquer forma, é preciso analisar a forma que deve assumir a competição pelos escassos e fundamentais recursos energéticos fósseis, especialmente petróleo e gás natural, entre EUA e China nos próximos anos. A atual conjuntura de crescente escassez relativa de petróleo no mercado mundial, agravada principalmente por uma demanda superior à oferta total, complica a análise de cenários futuros, onde pode haver até mesmo escassez absoluta de petróleo. O que pode ocorrer tanto em virtude das guerras locais e possíveis colapsos regionais de mercados produtores como pelo esgotamento dos principais campos produtores mundiais de petróleo convencional.

Como anteriormente citado, a ameaça deste tipo de cenário é que tanto os Estados Unidos como a China possam acreditar que o crescimento do consumo energético do outro é uma ameaça ao seu próprio crescimento, ou até mesmo à sua própria sobrevivência econômica, social e política. Se a competição sino-americana assumir forma antagonística, expressa em inimizade política e preparação militar, a transição sistêmica pode culminar em guerras de largas proporções. Este não seria o cenário esperado pelo governo chinês, que no momento tenta a todo custo preservar a estabilidade da ordem mundial.

Com efeito, a preservação de tal estabilidade pode garantir à China a redução da distância do nível de desenvolvimento que ainda a separa dos países ocidentais, ao mesmo tempo em que a situaria no núcleo do sistema internacional. Ou seja, a China precisa continuar crescendo para manter a unidade política, só que para isso precisa manter o suprimento de recursos naturais, especialmente energéticos. Se a transição no curto prazo se refere às disputas sino-americanas, no longo prazo deverá ser do modelo de desenvolvimento e do padrão de consumo compatível com a emergência chinesa. 


\section{Notas}

1. A importância desta organização será mais bem discutida adiante. Por enquanto, vale destacar que a Organização de Cooperação de Shangai foi formada em 2001 e, além de China e Rússia, é integrada por Cazaquistão, Quirguistão, Tadjiquistão e Usbequistão. Mais informações podem ser obtidas no site oficial da OCS: <http://www.sectsco.org/>. Acesso em: nov. 2007.

2. Entende-se por hegemonia o poder consentido (ARRIGHI; SILVER, 2001, p. 35-36). Nesse sentido, a noção de recomposição da hegemonia dos EUA expressa-se pela resistência à emergência de pólos desafiantes, recompondo, portanto, a legitimidade da liderança e, por sua vez, reduzindo a necessidade relativa de recurso à força e à coerção. Portanto, a hegemonia refere-se à liderança ou superioridade não apenas militar, mas também necessariamente nos planos político, econômico e cultural-ideológico.

3. A classificação da polaridade do sistema internacional também gera muitos debates e controvérsias. Buzan e Waever (2003, p. 31-39) propõem um esquema analítico-explicativo que considera como polaridade o número de pólos de poder que podem ser classificados de forma geral segundo sua atuação predominante (local, regional, inter-regional, global), sendo determinante para o status da polaridade mundial o número de pólos (BUZAN; WAEVER, 2003, p. 34-37) que podem ser considerados como superpotências ou grandes potências.

4. No Brasil, a arrancada desenvolvimentista pós-1930 também foi uma resposta ao ciclo depressivo da economia mundial, colocando o país diante de uma crise comercial e conseqüente escassez de moeda forte, o que condicionou a substituição de importações e a emergência de um novo pacto de poder político. Ver Rangel (2005).

5. O NIGCOMSAT-1, financiado por US\$ 200 milhões pelo governo chinês, foi lançado por um foguete Longa Marcha 3-B. Para mais detalhes, ver Xuequan (2007).

6. Para uma interessante análise entre "missão civilizadora" com política imperial, ver Losurdo (2006).

7. Asean+3 é o grupo formado em 1997 pela Association of Southeast Asian Nations (Asean; em português, Associação das Nações do Sudeste Asiático) mais Japão, China e Coréia.

8. Para um interessante balanço da geopolítica clássica, ver Mello (1999). 
9. O projeto de construir um novo "século norte-americano" no século XXI é a principal bandeira do think tank Project for the New American Century (PNAC), que tem entre seus membros fundadores William Kristol e Robert Kagan. Entre os signatários do Statement of Principles do PNAC, encontram-se importantes representantes do pensamento neoconservador norte-americano como: Dick Cheney, Donald Rumsfeld, Paul Wolfowitz, Robert Zoellick, Eliot A. Cohen e Francis Fukuyama. Até maio de 2008, o PNAC mantinha um site disponível na internet, <http://www.newamericancentury.org/>, que foi retirado e no momento está indisponível. Uma cópia do antigo site está disponível em: <http://web.archive.org/web/*/www.newamericancentury.org/>.

10. Tanto que o consumo total de combustíveis fósseis só aumentou nas últimas décadas.

11. A dependência de uma fonte de energia importada e de um único fornecedor fragiliza enormemente a estabilidade e a segurança energética de um país ou região. O caso recente do corte no fornecimento de gás russo à Ucrânia, em pleno inverno de 2005-2006, afetando inclusive o restante do mercado europeu, é um caso emblemático do quanto este problema continua sendo atual. Em outro contexto, o Brasil também vem enfrentando problemas com o fornecimento de gás boliviano, que não chegou a ser cortado, mas serviu para ilustrar a insegurança do setor energético brasileiro, que aparentemente só não teve que ceder mais porque a Bolívia também depende quase exclusivamente do mercado brasileiro para exportar seu gás.

12. Apenas entre janeiro e agosto de 2007 o consumo de petróleo na China cresceu $18 \%$.

13. Para visualizar de forma breve o debate a respeito do problema do pico de produção petrolífera, ver Oliveira (2007, p. 46-52, p. 56-60).

14. Como demonstrado pelo modelo do geólogo Marion King Hubbert, em diversos campos ou bacias petrolíferas, alguns anos, ou décadas depois do pico das descobertas, atinge-se o pico produtivo. A capacidade máxima de produção, ou pico produtivo, pode durar alguns anos, mas a seguir a produção entra em declínio ou depleção, sendo difícil revertê-la, a não ser que sejam feitas novas grandes descobertas de petróleo. O tempo necessário para começar a depleção depende da relação entre volume total das reservas e velocidade do consumo. Como demonstrado por Hubbert, geralmente a produção máxima, ou pico de produção, ocorre muito próximo do momento em que metade das reservas totais foi consumida. Para uma descrição mais detalhada do modelo de Hubbert, ver Campbell e Laherrère (1998) e Campbell (2005). 
15. Segundo a OPEP (2004), a atual produção chinesa de 3,2 milhões de b/d deverá aumentar para cerca de 3,8 em 2015, mantendo-se neste patamar até por volta de 2020, quando começará a cair, atingindo cerca de 3,6 milhões de b/d a partir de 2025.

16. Dados do BP statistical review of world energy full report 2005 (BRITISH PETROLEUM, 2005), OPEC annual report 2005 (OPEP, 2006a) e OPEC annual statistical bulletin 2005 (OPEP, 2006b).

17. A China National Petroleum Coporation (CNPC) comprou em 2005 a PetroKazakhstan, que, mesmo não significando grandes reservas ou produção, reforça a ascendência chinesa sobre a estratégica Ásia Central (CARTA DA CHINA, 2005a).

18. A classificação de Torres Filho (2004) resume as principais características dos sistemas de ordenamento do mercado petrolífero mundial, como tendência do consumo, sistema de formação dos preços, capacidade ociosa, os tipos de contratos, acordos e instrumentos de suporte ao mercado, o tipo de equilíbrio de mercado, o país "ofertante" em última instância (EUA ou Arábia Saudita) e o tipo de segurança interna e externa do Golfo Pérsico. A partir do conjunto destas características, o autor divide o período pós-Segunda Guerra Mundial em três: o de consolidação da hegemonia norte-americana (1945-1973), o do condomínio saudita-norte-americano-iraniano (1973-1985) e o do mercado flexível com presença militar norte-americana no Golfo Pérsico (1985-2002).

19. A CNPC comprou em 2005 a seção da petrolífera canadense EnCana Corp., que atuava no Equador (CARTA DA CHINA, 2005b) e no Chade.

20. Como demonstra a recente mudança de postura do Chade, país que começou a exportar petróleo apenas recentemente e que após pressões do governo de Pequim, em agosto de 2006, rompeu relações diplomáticas com Taiwan, reconhecendo apenas a República Popular da China. Ver Chad cuts (2006) e Chad chooses (2006).

21. De um total mundial avaliado pela OPEP em 180 trilhões de metros cúbicos (OPEP, 2006b, p. 22).

22. Ver Embaixada da República Popular da China no Brasil (2006).

23. Por geopolítica, aqui se entende a "formulação das teorias e projetos de ação voltados às relações de poder entre os Estados e às estratégias de caráter geral para os territórios nacionais e estrangeiros" (COSTA, 1992, p. 16). 


\section{Referências Bibliográficas}

ARRIGHI, Giovanni; SILVER, Beverly J. Caos e governabilidade no moderno sistema mundial. Rio de Janeiro: UFRJ, Contraponto, 2001.

BIJIAN, Zheng. China's "peaceful rise" to great-power status. Foreing Affairs, set./out., v. 85, n. 5, 2005.

BLAIR, Bruce; YALI, Chen; HAGT, Eric. The oil weapon: myth of China's vulnerability. China Security, n. 2, Summer 2006. Disponível em: <http://www.wsichina.org/\%5Ccurr03.html>. Acesso em: 22 jul. 2008.

BRITISH PETROLEUM. BP statistical review of world energy full report 2005. Jun. 2005. Disponível em: <http://www.bp.com/liveassets/bp_internet/ globalbp/globalbp_uk_english/publications/energy_reviews_2005/ STAGING/local_assets/downloads/pdf/statistical_review_of_world_energy_ full_report_2005.pdf>. Acesso em: 2 ago. 2007.

. BP statistical review of world energy 2006. Jun. 2006. Disponível em: $<$ http://www.bp.com/statisticalreview>. Acesso em: 9 ago. 2006.

. BP statistical review of world energy 2007. Jun. 2007a. Disponível em: <http://www.bp.com/statisticalreview>. Acesso em: 7 jul. 2007.

BP statistical review full report workbook 2007. Historical data from 1965-2006. Historical Data Series, Oil Inter-Area Movement. Jun. 2007b. Disponível em: <http://www.bp.com/statisticalreview>. Acesso em: 7 jul. 2007.

BRZEZINSKI, Zbigniew. El gran tablero mundial: la supremacia estadunidense y sus imperativos geoestratégicos. Buenos Aires: Ed. Paidós, 1997.

. The geostrategic triad: living with China, Europe and Russia. Significant issues series. Washington D.C.: Center for Strategic and International Affairs, 2001.

BUZAN, B.; WAEVER, Ole. Regions and powers - the structure of international security. Cambridge: Cambridge University Press, 2003.

CAMPBELL, Colin J. Oil crisis. Bretwood, Essex: Multi-Science Publishing, 2005 
; LAHERRÈRE, J. H. The end of cheap oil. Scientific American, mar. 1998. Disponível em: <http://dieoff.com/page140.pdf>. Acesso em: 22 jul. 2008 .

CARTA DA CHINA. Rio de Janeiro: Conselho Empresarial Brasil-China, ano 2, n. 11, 8 set. 2005a. Disponível em: <http://www.cebc.org.br/sites/500/521 /Carta_da_China_11-08set2005.pdf>. Acesso em: 22 jul. 2008.

Rio de Janeiro: Conselho Empresarial Brasil-China, ano 2, n. 12, 7 out. 2005b. Disponível em: <http://www.cebc.org.br/sites/500/521/download/CartadaChina12-07out2005.pdf>. Acesso em: 22 jul. 2008.

CHAD CHOOSES China over Taiwan. BBC News, 7 ago. 2006. Disponível em: <http://news.bbc.co.uk/2/hi/asia-pacific/5251762.stm>. Acesso em: 9 jul. 2008.

CHAD CUTS diplomatic ties with Taiwan. China Daily, 6 ago. 2006. Disponível em: <http://www.chinadaily.com.cn/china/2006-08/06/content_657968. htm>. Acesso em: 9 jul. 2008.

CHUNG, Chien-peng. The Shanghai Co-operation Organization: China's changing influence in Asia Central. China Quarterly, v. 180, p. 989-1.009, Dec. 2004. Disponível em: <http://journals.cambridge.org/download. php?file $=\% 2 F C Q Y \% 2 F C Q Y 180 \% 2 F S 0305741004000712$ a.pdf \&code $=3 f 9 f$ 195128e304273592b187924f0996>. Acesso em: 22 jul. 2008.

COSTA, Wanderly. Geografia política e geopolítica. São Paulo: EdUSP, Hucitec, 1992.

DAOJIONG, Zha. Energy interdependence. China Security, n. 2, Summer 2006.

EMBAIXADA DA REPÚBLICA POPULAR DA CHINA NO BRASIL. China procura ampliar cooperação petrolífera com OCS. 18 jun. 2006. Disponível em: <http://www.embchina.org.br/por/jmwl/t258624.htm>. Acesso em: 4 abr. 2007.

HUNTINGTON, Samuel. O choque de civilizações. São Paulo: Objetiva, 1997.

JABBOUR, Elias. China: infra-estrutura e crescimento econômico. São Paulo: Anita Garibaldi, 2006. 
KLARE, Micahel. The new geography of conflict. Foreign Affairs, v. 80, n. 3, p. 49-61, May/June 2001.

. Guerras por los recursos - el futuro escenario del conflicto global. Barcelona: Ed. Urano, 2003.

. El ocaso de la era del petroleo. 2005. Disponível em: <http://rcci.net/globalizacion/2005/fg551.htm>. Acesso em: 10 jan. 2006.

LOSURDO, Domenico. Fuga da história? Rio de Janeiro: Revan, 2004.

Liberalismo - entre a civilização e a barbárie. São Paulo: Anita Garibaldi, 2006.

MELLO, Leonel. Quem tem medo de geopolítica? São Paulo: EdUSP, 1999.

NATIONAL BUREAU OF STATISTICS OF CHINA. China statistical yearbook. 1980-2005. Disponível em: <http://www.stats.gov.cn/english/>. Acesso em: 22 jul. 2008.

OLIVEIRA, Lucas. Petróleo e segurança internacional: aspectos globais e regionais das disputas por petróleo na África Subsaariana. Dissertação (Mestrado em Relações Internacionais ) - Universidade Federal do Rio Grande do Sul, Porto Alegre, 2007.

OPEP. Oil outlook to 2025. OPEC review paper. 2004. Disponível em: <http://www.opec.org/library/OPEC\%20Review/OWEM04.pdf>. Acesso em: 22 jul. 2008.

OPEP. OPEC annual report 2005. 2006a. Disponível em: <http://www.opec. org/library/Annual\%20Reports/pdf/AR2005.pdf>. Acesso em: 15 set. 2006.

OPEP. OPEC annual statistical bulletin 2005. 2006b. Disponível em: $<$ http://www.opec.org/library/Annual\%20Statistical\%20Bulletin/pdf/ ASB2005.pdf>. Acesso em: 18 nov. 2006.

OPEP. OPEC interactive annual statistical bulletin 2006. Table 33. 2006c. Disponível em: <http://www.opec.org/library/Annual\%20Statistical\%20Bulletin/interactive/FileZ/XL/T33.XLS>. Acesso em: 18 nov. 2006.

PAUTASSO, Diego. A China na transição do sistema mundial. Dissertação (Mestrado em Ciência Política) - Universidade Federal do Rio Grande do Sul, Porto Alegre, 2006. 
RANGEL, Ignácio. A história da dualidade brasileira. In: Obras reu-

nidas. v. 2. Rio de Janeiro: Contraponto, 2005. p. 655-685.

SPENCE, Jonathan. Em busca da China moderna. São Paulo: Companhia da Letras, 1995.

SWAINE, Michal; TELLIS, Ashley. Interpreting Chinas's grand strategy: past, present and future. Santa Monica: RAND, 2000.

TODD, Emmanuel. After the empire: the breakdown of the American order. New York: Constable, 2003.

TORRES FILHO, Ermani T. O papel do petróleo na geopolítica americana. In: FIORI, José Luís. O poder americano. Petrópolis: Ed. Vozes, 2004.

VIZENTINI, Paulo; RODRIGUES, Gabriela. O Dragão Chinês e os Tigres Asiáticos. Porto Alegre: Leitura XXI, 2000.

XUEQUAN, Mu. China launches communications satellite for Nigeria. China View, 14 mai. 2007. Disponível em: <http://news.xinhuanet.com/english/ 2007-05/14/content_6094120.htm>. Acesso em: 9 jun. 2008.

YERGIN, Daniel. O petróleo: uma história de ganância, dinheiro e poder. São Paulo: Ed. Página Aberta, 1993.

WENMU, Zhang. Sea power and China's strategic choices. China Security, n. 2, Summer 2006. Disponível em: <http://www.wsichina.org/cs3_2.pdf>. Acesso em: 22 jul. 2008. 


\section{Resumo}

\section{A Segurança Energética da China e as Reações dos EUA}

O objetivo deste artigo é analisar a busca da China por segurança energética e as reações dos EUA, bem como seus desdobramentos para a política internacional. $\mathrm{O}$ argumento central é que a ascensão chinesa tem dependido do suprimento energético externo, que, por sua vez, revela o crescimento das disputas com os EUA em um cenário internacional de reorganização de forças.

Palavras-chave: China - Segurança Energética - EUA - Reorganização de Forças

\section{Abstract}

\section{China's Energy Security and USA Reactions}

The objective of this paper is to analyze China's quest for energetic security and USA reaction, as well as its consequences for the international politics. The central debate is the Chinese ascension depend of external energetic supply that, consequently, unveiling the growing disputes with the USA in a scenario of international reorganization of forces.

Keywords: China - Energetic Security - USA - Reorganization of Forces 